\title{
First year with COVID-19: Assessment and prospects
}

\author{
Robert Bergquist, ${ }^{1}$ Behzad Kiani, ${ }^{2}$ Samuel Manda ${ }^{3}$ \\ ${ }^{1}$ Ingerod, SE-454 94 Brastad, Sweden; ${ }^{2}$ Department of Medical Informatics, School of Medicine, Mashhad \\ University of Medical Sciences, Mashhad, Iran; ${ }^{3}$ Biostatistics Unit, South African Medical Research \\ Council; Department of Statistics, University of Pretoria, Pretoria, South Africa
}

The vision of health for all by Dr. Halfdan Mahler, Director General of the World Health Organization (WHO) 1973 to 1988, guided public health approaches towards improving life for all those mired in poverty and disease. Research on the Neglected Tropical Diseases (NTDs) of the world's poor was advancing strongly when the coronavirus disease 2019 (COVID-19) struck. Although work on the NTDs did not grind to a halt, the situation is reminiscent of the author Stefan Zweig's passionate account of culture destruction in his book The World of Yesterday from 1941, which gives an insight as to how the war ended traditional life. His thoughts parallel the present situation; however, this time societies are not torn apart by war but instead isolated by a pandemic. It comes upon today's scientists to move fast to make COVID-19 less devastating than the Spanish flu of 1918-1920 that killed more than $3 \%$ of the world population.

One year has passed since the first reported case of COVID19 was diagnosed in China (Ma, 2020). Despite fervent efforts to limit the disease, it swiftly spread worldwide exerting a severe impact on human wellbeing and straining the world economy. After a surreptitious lull in the summer 2020, COVID-19 now shows an ominously strong, upward trend with the total, cumulative number of cases quickly moving past the levels of 40 and 50 million infected. Even though $75 \%$ have fully recovered, many active cases remain and a staggering million+ lives have been claimed. Lacking effective pharmaceutical interventions, national government efforts to control transmission are limited to intermittent lockdowns and asking people to keep distance, employ strict hand hygiene and wear face masks. On the positive side, many vaccine candidates have been developed at an astounding speed, and it is highly probable that at least a few of those currently in Phase- 3 clinical trials will soon be released. This will usher in the proactive approach required to get the upper hand in the fight against COVID-19, a prospect supported by recent reports of

Correspondence: Robert Bergquist, Ingerod, Brastad, Sweden.

E-mail: editor@geospatialhealth.net

Received for publication: 28 October 2020.

Accepted for publication: 28 October 2020.

(C) Copyright: the Author(s), 2020

Licensee PAGEPress, Italy

Geospatial Health 2020; 15:953

doi:10.4081/gh.2020.953

This article is distributed under the terms of the Creative Commons Attribution Noncommercial License (CC BY-NC 4.0) which permits any noncommercial use, distribution, and reproduction in any medium, provided the original author(s) and source are credited. active cell-mediated immunity (Sekine et al., 2020) and lasting, specific antibodies (Gudbjartsson et al., 2020). The fact that many previous, equally serious infectious diseases, smallpox, polio and influenza among them, were overcome by large-scale vaccination strengthens the likelihood of a positive outcome of this strategy.

So far, China seems to be the only country having conquered COVID-19 (mainly based on strict lockdown, large-scale testing and contact-tracing), while some countries have largely avoided it, e.g., New Zeeland and Australia. In Africa, the response to the pandemic has been diverse, with many countries not being able to institute and enforce rigid lockdowns as the economic fallout would far outweigh the risk of the pandemic. In addition, few African governments have the funds to sustain complete and prolonged lockdowns without international aid to support the livelihood of their citizens. Undoubtedly, however, the situation easily gets out of hand when containment efforts are lax or when agreed approaches are not enforced.

\section{Testing, the key to real-time prediction}

When the incidence rates between countries are compared, both the number of tests conducted and the number of national inhabitants must be considered. Case counting is a treacherous exercise for several reasons. Importantly, it is not clear if the reported number of tests refers to having demonstrated the virus in people's respiratory airways (seemingly the most common approach), or if it concerns circulating viral antigens, specific antibodies or other immune responses. Furthermore, the number of COVID-19 cases discovered depends strongly on the number of tests carried out, which is exemplified by data from South Africa as shown in Figure 1. There is obviously a high correlation between testing and reported case counts already from the very early stages of the pandemic, a situation presumably repeated also in other countries, something which impedes straightforward comparisons. In addition, the true number of infections is generally much higher than the official data indicate since up to $80 \%$ of those infected can be asymptomatic (Heneghan et al., 2020).

While previously only those suspected of being infected were subjected to testing, people are now increasingly prone to using voluntary testing, in particular since negative COVID-19 test results are becoming a requirement for travel between countries. Assuming that travellers are then more likely to be non-infected by the coronavirus, the number of positive infections would be diluted and thus artificially improve the situation. Indeed, the number of cases reported in recent months cannot be directly compared with those reported at the beginning of the infection wave in March and April 2020, as they almost entirely consisted of hospitalized cases. Figure 2 illustrates the effect of the dilution factor, since the Case Fatality Rate (CFR) initially rapidly rose but later entered a downward slope 
as testing became more widely applied. It can thus be concluded that mortality estimates will likely continue on the downward trend, even if the total case count increases. Thus, the higher the testing rate, the closer the CFR moves to its true value, which is particularly well

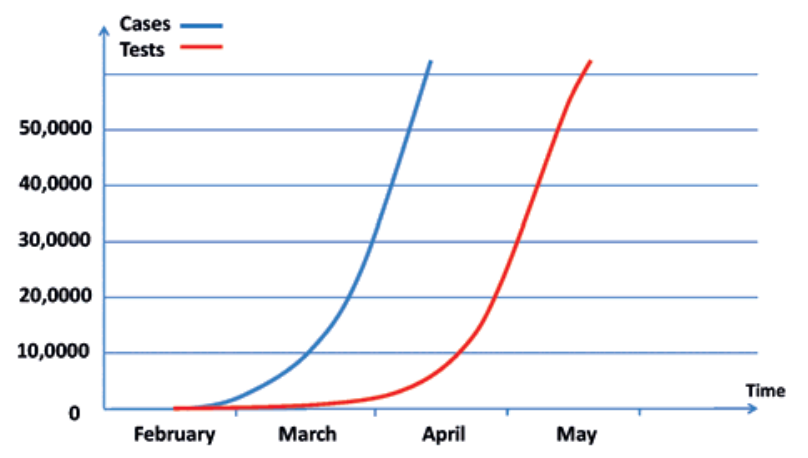

Figure 1. Cumulative numbers of COVID-19 cases and tests at the beginning of the pandemic in South Africa based on the South African COVID-19 Data Repository (https://github.com/dsfsi/ covid19z).

Figure 3 compares the results from three countries, two characterized by intensive testing (Iceland and Denmark) and one where a lower number of people were tested (Switzerland). The comparison may not be entirely correct since it assumes that an equal number of tests are carried out each day as well as testing being equally spread over the country, none of which can realistically be the case. The closer resemblance between results in the three countries in the more recent part of the period could, however, be explained by the higher testing activity during September-October 2020. Seen from this point of view, the transmission levels in countries having reached a high testing level, say daily examining 600-800 subjects per million inhabitants, might be comparable ceteris paribus (Figure 3). The results in the three countries clearly show the presence of two waves of infection, a fact also reflected in Figure 4 though less clearly so since the US, for example, only achieved a short-lived reduction in exemplified by the Icelandic study referred to above. With about $90 \%$ of the population tested, the CFR was just $0.3 \%$ (Gudbjartsson et al., 2020). Clearly, the recent generally lower mortality is also due to better knowledge and improved treatment.

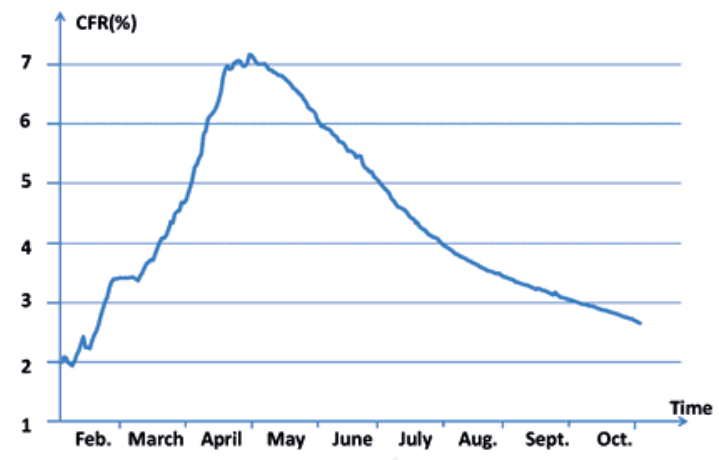

Figure 2. Development of the CFR due to COVID-19 February - October 2020 based on the daily publication of global, cumulative data by Worldometer (https://www.worldometers.info/coronavirus).

cases after the first wave. The cause of the two-wave dynamic is that the first virus attack is normally limited, particularly if weather conditions are fair, while minor kernels of infection remain in the population ready to strike again when the colder months force people indoors. Fading immunity in those who have had the infection can also play a role. The second wave is often stronger than the first, as seen in the graphs depicted in Figures 3 and 4. However, even these high levels have now been dwarfed by the developments at the very end of October with France reporting daily counts exceeding 600 cases per million inhabitants on and the Czech Republic double that number. The situation in the latter is of particular concern as the record-breaking high number of people infected by the coronavirus was accompanied by an unusually high death toll and reached in just a few weeks after a long period of negligible levels without a noticeable first wave.

\section{COVID-19 Infections and Testing Intensity in Various Countries during February-October 2020.}

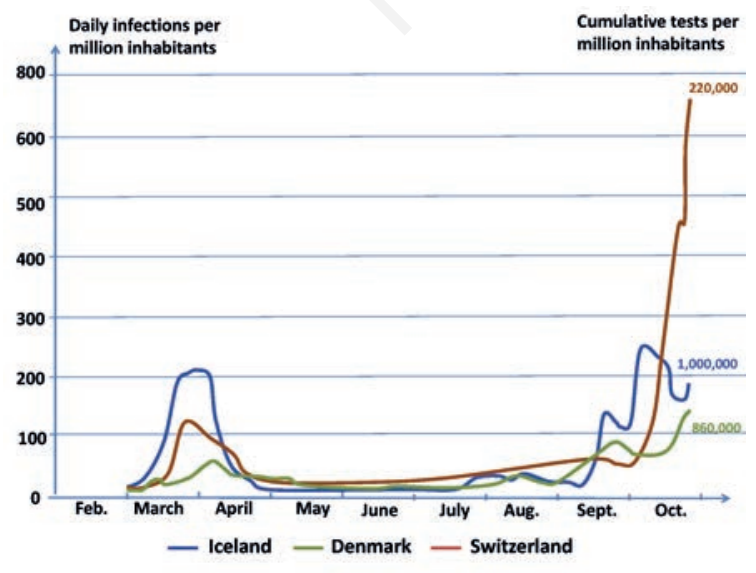

Figure 3. Graph based on 7-day moving averages of daily data reported by Worldometers in Iceland, Denmark and Switzerland (https://www.worldometers.info/coronavirus/).

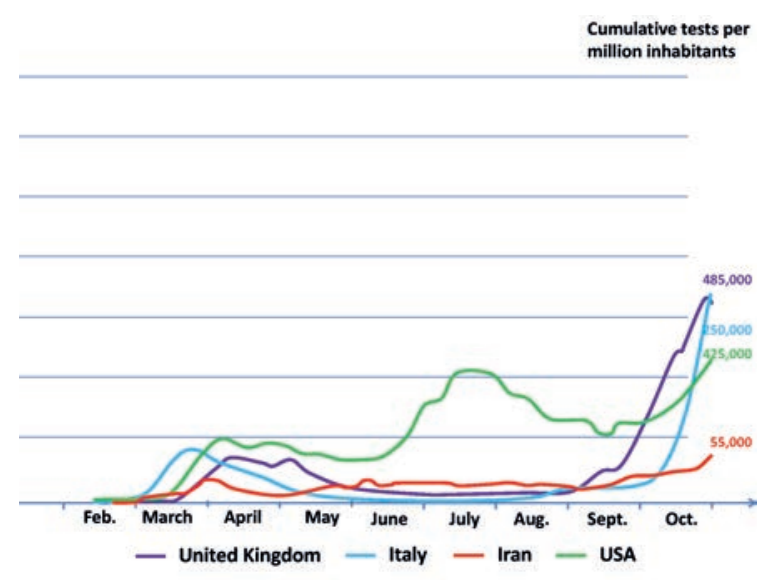

Figure 4. Graph based on 7-day moving averages of daily data reported by Worldometers in United Kingdom, Italy, Iran and USA (https://www.worldometers.info/coronavirus/). 
The recent, strong rise of COVID-19 infections in many countries may be related to inability to enforce unpopular strategies imposed by governments, while the less striking but overall increasing pattern seen in the US could instead be due to the absence of a unified central approach (Figure 4). For Iran, the graph also indicates an increasing rate of infection over time, but the number of infected people detected daily is too low to display a convincing double-wave pattern. The much higher daily levels of COVID-19 infection per million inhabitants reported from the three other countries at the end of October (Figure 4) could also be a reflection of higher testing rates.

\section{Geospatial approaches}

Any attempt to understand the transmission and spread of a pandemic must rely on dynamic approaches focused on population distribution and mobility (Leyk et al., 2019; Smith and Mennis, 2020), while at the same time keeping an eye on potential case clusters and their change in space and time. This issue of Geospatial Health includes two papers on COVID-19 infections in São Paulo, a hotspot of the infection in Brazil, one by Ferreira (2020) and the other by Alcântara et al. (2020). Both papers concern the spatial dependence of transmission, with the former reporting that the highest incidence in the first three months of the pandemic occurred in city districts characterized by low salaries and slums, surprisingly though with lower rates for people over 60 years old, while the latter focused on social isolation measures and noted that the incidence first increased in areas with the highest populations thereby slowing down the emergence of new confirmed cases there, something that could not be sustained. Importantly, the conclusion reached in the second paper was that the population density per se is not a key parameter to understanding COVID-19 mortality but rather the availability of hospital beds, implying that fatality depends substantially on the actual patient's precondition.

Use of location data based on mobile-phone records has already proved helpful for formulation of effective intervention strategies (Deville et al., 2014). Large-scale use of this approach not only marks a break-through for rapid follow-up, but is also useful for distributing personal instructions in the form of text messages. Social media can play an important role in this connection as shown by analysis of Twitter messages related to airline transportation (Bisanzio et al., 2020), while Lai et al. (2020) applied mobility data for transmission research focused at the city-level in China. Interestingly, Google now provides worldwide data with (anonymous) mobility reports of its users based on handheld devices showing movement between shops/supermarkets, streets, parks, restaurants, workplaces and hotels or private residences. Chan et al. (2020) have extracted this information from Google Community Mobility Reports offering support for mapping human movement in order to formulate appropriate scientific and policy responses with respect to the COVID-19 pandemic. Ready-to-use indexes of human mobility spanning 131 countries and territories and 830 sub-national regions are already available covering the period from 16 February to 10 April 2020 at https://osf.io/gyafe/ (country-level data) and at https://osf.io/chk2f/ (regional-level data) with updates for more recent times under development.

\section{COVID-19 transmission drivers}

Tentative results based on the mobility database mentioned indicate that large-scale congregations of people, such as team sports, concerts and other activities with large crowds, promote viral transmission more than any other activity. Naturally, however it is beyond the ability of governments to prevent every kind of gathering. In the US, political rallies have been pivotal in spreading the virus and the frequent visits and time spent in restaurants and pubs in Europe have been difficult to curb. Some modellers (Balcan et al., 2009; Gatto et al., 2012) argue that behavioural norms (culture) and regional differences (geography) strongly influence transmission. Indeed, racial and ethnic composition, life expectancy, population density, health care capacity and resilience have been shown to explain the geographical disparity in the COVID-19 burden and transmission (Sun et al., 2020; Cuadros et al., 2020). In Africa, limited evidence indicates that areas with higher rates of infectious diseases such as TB and HIV are more likely to incur high levels of COVID-19 infection. Behavioural norms may indeed, be part of the explanation for the high mortality in the early phase of the pandemic in Sweden, as this country had a usually strong wave of immigration in 2016 consisting of many still not well integrated with the host population (Economist, 2020). However, that would be just one of very many possible explanations as results vary considerably between countries.

\section{Conclusions}

Few pandemics have proved more severe than COVID-19, although the Spanish flu killed 50+ million people and the Black Death came close to ending human civilization (McNeill, 1976). In previous centuries, people just had to cope as best they could, while current recommendations issued by the WHO represent the first worldwide effort to temper the transmission of a pandemic. Although not popular, the universal embargo on sport and entertainment activities must be deemed useful as the global number of infections one year into the pandemic is much lower than any of the five previous influenza pandemics experienced since the late 1800 s. Whether or not effective vaccines will be available soon, large-scale testing must continue. Voluntary testing given for free, say by mobile clinics, just as is done for HIV in Africa, would be a useful step in this direction.

\section{References}

Alcântara E, Mantovani J, Rotta L, Park E, Rodrigues T, et al., 2020. Investigating spatiotemporal patterns of the COVID-19 in São Paulo State, Brazil. Geospat Health 15 [this issue].

Bisanzio D, Kraemer MUG, Bogoch II, Brewer T, Browstein JS, Reithinger R, 2020. Use of Twitter social media activity as a proxy for human mobility to predict the spatiotemporal spread of COVID-19 at global scale. Geospat Health 15:19-24. doi: $10.4081 /$ gh.2020.882.

Balcan D, Colizza V, Gonçalves B, Hu H, Ramasco JJ, Vespignani A, 2009. Multiscale mobility networks and the spatial spreading of infectious diseases. Proc Natl Acad Sci USA 106:21484-9.

Chan H, Skali A, Torgler B, 2020. A Global Dataset of Human Mobility. CREMA Working Paper Series. Center for Research 
in Economics, Management and the Arts (CREMA). Available from: https://ideas.repec.org/p/cra/wpaper/2020-04.html

Cuadros DF, Xiao Y, Mukandavire Z, Correa-Agudelo E, Hernández A, et al., 2020. Spatiotemporal transmission dynamics of the COVID-19 pandemic and its impact on critical healthcare capacity. Health Place 64:102404. doi:10.1016/j.healthplace.2020.102404

Deville P, Linard C, Martin S, Gilbert M, Stevens FR, et al., 2014. Dynamic population mapping using mobile phone data. Proc Natl Acad Sci USA 111:15888-93. doi: 10.1073/pnas. 1408439111

Economist, 2020. Coronavirus in Sweden: the odd one out. In issue dated October 10th 2020, p. 26. Available from: https://www. economist.com/

Ferreira MC, 2020. Spatial association between the incidence rate of COVID-19 and poverty in the São Paulo municipality, Brazil. Geospat Health 15 [this issue].

Ma J, 2020. Coronavirus: China's first confirmed COVID-19 case traced back to November 17. South China Morning Post of 13 March 2020. Available from: https://www.scmp.com/ news/china/society/article/3074991/coronavirus-chinas-firstconfirmedcovid-19-case-traced-back. Available from: www.scmp.com Accessed: 10 October 2020.

Gatto M, Mari L, Bertuzzo E, Casagrandi R, Righetto L, et al., 2012 Generalized reproduction numbers and the prediction of patterns in waterborne disease. Proc Natl Acad Sci USA 109:19703-8.

Gudbjartsson DF, Gudmundur L, Norddahl GL, Melsted P, Gunnarsdottir K, et al., 2020. Humoral Immune Response to
SARS-CoV-2 in Iceland. N Engl J Med [Online ahead of print]. doi:10.1056/NEJMoa2026116

Heneghan C, Brassey J, Jefferson T, 2020. COVID-19: What proportion are asymptomatic?. The Centre for Evidence-Based Medicine (CEBM). University of Oxford, UK. Available from: https://www.cebm.net/covid-19/covid-19-what-proportionare-asymptomatic/. Accessed: 15 October 2020.

Lai S, Ruktanonchai NW, Zhou L, Prosper O, Luo W, et al., 2020. Effect of non-pharmaceutical interventions to contain COVID19 in China. Nature 585:410-3. doi: 10.1038/s41586-0202293-x

Leyk S, Gaughan AE, Adamo SB, de Sherbinin A, Balk D, et al., 2019. The spatial allocation of population: a review of largescale gridded population data products and their fitness for use. Earth Syst Sci Data 11:1385-409.

McNeill WH. Plagues and peoples, 369 pp. W. W. Norton, New York; 1976.

Sekine T, Perez-Potti A, Rivera-Ballesteros O, Strålin K, Gorin JB, et al., 2020. Robust T Cell Immunity in Convalescent Individuals with Asymptomatic or Mild COVID-19. Cell 183:158-168.e14. doi: 10.1016/j.cell.2020.08.017.

Smith CD, Mennis J, 2020. Incorporating Geographic Information Science and Technology in Response to the COVID-19 Pandemic. Prev Chronic Dis 17:200246. doi:10.5888/pcd 17.200246

Sun F, Matthews SA, Yang TC, Hu MH, 2020. A spatial analysis of COVID-19 period prevalence in US counties through June 28, 2020: Where geography matters? Annal Epidemiol [Online ahead of print]. doi:10.1016/j.annepidem.2020.07.014 